\title{
Growth Mindset Leads Grittier Students
}

\author{
Fatin Rohmah Nur Wahidaha*, Lucia R M Royanto ${ }^{\mathrm{b}}$ \\ ${ }^{a}$ Faculty of Psychology, Universitas Muhammadiyah Purwokerto, Jalan Raya Dukuhwaluh, Banyumas, Jawa Tengah, 53182, Indonesia \\ ${ }^{b}$ Faculty of Psychology, University of Indonesia, Jalan Lingkar Kampus Raya, Depok, Jawa Barat 16424, Indonesia \\ *Corresponding author: fatinrohmahwahidah@ump.ac.id
}

Article history: Received: 11 January 2020 Received in revised form: 28 June 2020 Accepted: 10 May 2021 Published online: 09 August 2021

\begin{abstract}
This study investigates the relationship between a growth mindset and grit. The subjects involved in this study are students from high public and private schools in Purbalingga, Central Java $(\mathrm{n}=418)$. The research method used is a quantitative method with data collection through three sets of questionnaires, i.e., Mindset Scale (20 items, $\alpha=0.804$ ) and Grit Scale for Children and Adult (12 items, $\alpha=0.774)$. Results indicated a positive correlation between the growth mindset and grit. Grit also confirmed affected by a growth mindset $(\beta=0.445, \mathrm{p}<0.001)$. The growth mindset in students predicts grittier students to achieve goals and the best performance.
\end{abstract}

Keywords: grit; growth mindset; high schools; students

(C) 2021 Penerbit UTM Press. All rights reserved

\subsection{INTRODUCTION}

Grit is referred to as non-cognitive factors that consistently predict student success (Sturman \& Zappala-Piemme, 2017) because of their endurance in doing business, despite facing obstacles in achieving their long-term goals (Duckworth, 2016). Grit specifically talks about the persistence and passion of someone to achieve goals (Duckworth, 2016; Duckworth, Peterson, Matthews, \& Kelly, 2007). From various studies conducted by Duckworth (2016) on various samples and fields, he concluded that people who are successful or excel in any field have the determination and strength to survive. Persistent people will pursue something interesting and important to them, even if it's boring, frustrating, or painful. They never give up and remain passionate about it. Likewise, in the field of education, gritty students will find success because they strive to face challenges and maintain efforts to achieve their goals. Conversely, students who are not gritty will not succeed in gaining success because they stop trying when facing problems or difficulties (Duckworth, Peterson, Matthews, \& Kelly, 2007; Duckworth \& Quinn, 2009).

In several studies in the education field, grit has been widely explained about student academic performance (Duckworth, Peterson, Matthews, \& Kelly, 2007; Duckworth \& Quinn, 2009). Grit is known to be positively related to student learning outcomes (Zhao et al, 2018). Students who are grittier in dealing with higher GPA scores are even stronger when their university entrance selection scores are considered constant (Duckworth \& Eskreis-Winkler, 2015). In the group of black men who generally rarely go on to college, the relationship of grit and GPA score also remains valid. Black students who are grittier have grades in high school, university entrance scores and higher GPA scores (Strayhorn, 2014). Besides, grit is known to predict high school student graduation. New students in the first year of high school who are grittier have a higher likelihood of graduating from high school promptly (Duckworth \& Eskreis-Winkler, 2015) although other variables have been controlled (school motivation, standardized test scores, and demographics). Besides, grit is known to correlate with the level of student education. The grittier student, the higher the formal education he attains (Duckworth, 2016).

Some literature states that one of the factors that influence grit is a growth mindset. Dweck explained, students with a growth mindset assume that their intelligence and abilities can change so that they are more diligent and focused on long-term learning and appreciate the work done (Hochanadel \& Finamore, 2015). Students with a growth mindset will be more motivated to engage in challenging tasks or situations, learn from mistakes, and improve their performance until finally, they reach higher achievements (Blackwell, Trzesniweski, \& Dweck, 2007; Jach, Sun, Chin, Loton, \& Waters, 2017). Students with growth mindset interpret obstacles, challenges, and efforts as effective things to improve ability, intelligence, and experience (Zeng, Hou, \& Peng, 2016) so that they continue to believe that they can still learn and perform better in the future (Dweck in Duckworth, 2016). Some previous studies confirmed that a growth mindset affects the grit of students to continue learning and going to school (Chrisantiana \& Sembiring, 2017; Renaud-Dubé, Guay, Talbot, Taylor, \& Koestner, 2015; Zhao et al., 2018). However, some studies find a weak relationship between grit and mindset in high school students in South Africa (Kench, Hazelhurst, \& Otulaja, 2016).

This research was conducted in the context of secondary education involving 12th-grade high school students in the Purbalingga area, Central Java, Indonesia. Students in this level of education are facing crucial teenage years and high academic demands, so it is said to have many challenging things. This study uses a non-experimental design that will examine the relationship between a growth mindset and grit. The question to be answered in this research is "Does growth mindset have a significant effect on the persistence of high school 
students in Purbalingga?" The alternative hypothesis in research is that growth mindset has a significant effect on the grit of high school students in Purbalingga.

This study was conducted, bearing in mind the important role of growth mindset and grit in education. Also, there is still a lack of research in Indonesia that discusses the relationship between the growth mindset and grit, including its relationship with high school students. The results of this study are expected to contribute positively related to the results of the growth mindset and grit research in students.

\subsection{LITERATURE REVIEW}

\section{Grit}

The concept that sustained effort and focused interest contribute to success has been discussed in the psychological literature for more than a century by Galton in 1892. Galton proposed that talent alone was not sufficient for extraordinary achievements. On the contrary, the most superior people are shown by a combination of abilities between 'spirit' and 'capacity for hard work' (Duckworth \& Eskreis-Winkler, 2015). Research by Duckworth supports the opinion of Galton who later became better known as grit. By Duckworth, this term was popularized and defined as the ability to remain firm on one thing for a long period until he succeeded in mastering it (Hanford, 2013).

Besides Duckworth, one of the most recent studies of grit was conducted by Sturman and Zappala-Piemme (2017). After studying the results of studies and the Grit-O Scale made by Duckworth, they did not agree to involve a dimension of consistency in interest in grit. This is considered less related to collectivist culture (Li, Zhao, Kong, Du, Yang, \& Wang, 2018; Suzuki, Tamesue, Asahi, \& Ishikawa, 2015; Datu, Yuen, \& Chen, 2018; Jin \& Kim, 2017). According to them, the interest that changes from year to year does not indicate the weakness of one's grit. Broad and changeable interest in a person is not a problem, as long as he can stay focused on what he is doing or what he is aiming for.

Sturman and Zappala-Piemme (2017) then define grit as a focused effort to achieve the success of a task despite having to face various obstacles and the ability to overcome these obstacles. It can be concluded that grit places more emphasis on the aspects of effort that are maintained for a long time, even though in the process there are obstacles. In other words, grit is more related to business perseverance than the consistency of interest in a collectivist culture. Based on this, researchers consider the views of Sturman and Zappala-Piemme (2017) to be used in research, given that Indonesia tends to embrace the collectivist culture.

Grit makes students strive to face challenges, have high standards, focus on achieving goals, and continue to show effort even though failure, difficulty, and despair always confront (Duckworth \& Eskreis-Winkler, 2015; Akbağ \& Ümmet, 2017). Students who are grit do not give up easily and are increasingly encouraged to overcome every obstacle that exists (Akbağ \& Ümmet, 2017). Students who are grit tend to be optimistic, have good expectations, and will not be easily distracted from their goals (Jin \& Kim, 2017). On the other hand, students who are not persistent will not succeed in gaining success because they stop trying when facing problems or difficulties (Duckworth, 2016).

\section{Growth Mindset}

Dweck (2006) introduced a concept called mindset. Mindset describes a set of assumptions or ways of looking at individuals regarding personal qualities (abilities, character, potential, and intelligence) that they have whether they tend to be permanent or changeable (Yeager \& Dweck, 2012). Students will have a different mindset, starting from a fixed mindset to a growth mindset.

Students with a fixed mindset believe that their abilities, character, potential, and intelligence are innate, tend to stay, and cannot change. Students who have a fixed mindset lack positive beliefs related to self capacity and show a lack of effort and achievement (Blackwell, Trzesniweski, \& Dweck, 2007; Hochanadel \& Finamore, 2015). At school, he tends to feel threatened when facing failure and gives negative emotions to various experiences with the school context (King, 2017).

Students with a growth mindset believe that their abilities, characters, potential, and intelligence can change and develop over time (Yeager \& Dweck, 2012; Hochanadel \& Finamore, 2015). They also believe that their success is based on hard work, learning, perseverance, and practice so that they always learn from failure and continue to improve their performance (Shaari, Amar, Harun, \& Zainol, 2017). They are more able to overcome difficulties in the task and are more motivated in challenging situations, not just basing on their current abilities (Jach, Sun, Loton, Chin, \& Waters, 2017), and not contributing to helpless so that they will be more positive and want to look for strategies to try more when faced with failure (Blackwell, Trzesniweski, \& Dweck, 2007).

\subsection{METHODOLOGY}

This study uses a quantitative approach. This approach allows for the quantification of variations in a phenomenon. The data used in this study are in the form of numbers for subsequent statistical analysis (Gravetter \& Forzano, 2012). The research design used was a crosssectional design. This research will involve participants with one-time data retrieval in different individuals. This research belongs to the non-experimental research design. The researcher collected data using a questionnaire, not a direct experiment. The implementation is done in natural settings, there is no manipulation of the variables used, there is no randomization process, and researchers do not have direct control over the dependent variable (Gravetter \& Forzano, 2012).

The population of this study was all high school students in Purbalingga, Central Java, Indonesia. The sample of this research is high school students from eight schools (public schools and private schools) grade 12. The sampling method is non-probability sampling with an accidental sampling technique. This technique is a sampling technique that is based on the willingness of participants in the field (Gravetter \& Forzano, 2012). A booklet is given to participants randomly, containing several participant demographic questions, (such as 
age, gender, school origin) and two instruments (mindset scale and grit scale). Scores obtained from the questionnaire then processed and analyzed using SPSS 22.0.

\section{Research Instruments}

\section{Mindset Scale}

This instrument was developed by Chrisantiana and Sembiring (2017), referring to the theory of Dweck (2006), consisting of 21 items, each item has four choices of answers $(1=$ strongly disagree to $4=$ strongly agree $)$, using the Indonesian language, and has a coefficient $\alpha$ $=0.789$. The resulting score is a single score. The higher the score, shows the higher the growth mindset they have. Here follows a mindset scale grid in Table 1 .

Table 1 Mindset scale grid

\begin{tabular}{llll}
\hline \multicolumn{1}{c}{ Aspects } & $\begin{array}{l}\text { Positive Items } \\
\text { (Favorable) }\end{array}$ & $\begin{array}{c}\text { Negative Items } \\
\text { (Unfavorable) }\end{array}$ & \multicolumn{1}{c}{ Example Items } \\
\hline $\begin{array}{l}\text { Beliefs about intelligence, talent, and nature are things that } \\
\text { can be changed or permanent things. }\end{array}$ & $1,5,17,19$ & $2,6,9,11,12$ & $\begin{array}{l}\text { Intelligence is not a static thing } \\
\text { but can be improved } \\
\text { Challenges are opportunities to } \\
\text { Belief in challenges, difficulties, and failures is important for } \\
\text { self-development or a threat to self-image. }\end{array}$ \\
$\begin{array}{l}\text { Confidence about effort whether the effort and hard work } \\
\text { will not be able to make someone break through his limits or } \\
\text { the business will contribute to success. }\end{array}$ & $4,10,21$ & $3,7,15$ & $\begin{array}{l}\text { Smart people don't need to work } \\
\text { hard to complete a task }\end{array}$ \\
$\begin{array}{l}\text { Confidence in criticism and input received from others } \\
\text { whether it can be used as feedback to break the boundary or } \\
\text { merely to develop pre-existing potential. }\end{array}$ & 13 & 8,16 & $\begin{array}{l}\text { Criticism and input from others } \\
\text { will not be able to change my } \\
\text { condition }\end{array}$ \\
\hline
\end{tabular}

The reliability test of this measuring instrument against 62 students showed a coefficient $\alpha$ of 0.780 . The item validity test shows four invalid items (score corrected item-correlation items between -0.106 to 0.161 ). One item of negative value $(-0,106)$ was deleted and three other items were revised. Hence, there are 20 items-Mindset Scale that used in this research. The coefficient value $\alpha$ becomes 0.804 .

\section{Grit Scale}

Grit Scale for Children and Adult (GSCA) from Sturman and Zappala-Piemme (2017) is the result of the revised Grit-O Scale. This measure is considered more suitable for the population of young students and collectivist cultures. There is already an instrument that was adapted in Indonesian by Bintamur (2018) and has tested on 114 students of higher education $(\alpha=0.83)$. Although testing of this instrument was previously conducted on students of higher education, it was made for students ranging from elementary to college school (Sturman \& Zappala-Piemme, 2017) so that, this scale is still considered for use in research. The GSCA consists of 12 items and produces a single score on a 6 -point Likert scale (point $1=$ Strongly disagree, up to point $6=$ Strongly agree).

The results of testing reliability and validity of instruments known that the alpha coefficient is 0.809 . While the results of the validity test, the whole item in the measuring instrument has a corrected item-correlation score ranging from 0.209 to 0.657 . The system items for measuring persistence are presented in Table 2 .

Table 2 Grit scale grid

\begin{tabular}{lll}
\hline \multicolumn{1}{c}{ Items } & \multicolumn{1}{c}{ Item Number } & \multicolumn{1}{c}{ Example Items } \\
\hline Positive (Favorable) & $2,4,5,8,9,11,12$ & continued to work on my assignment until it was completed \\
Negative (Unfavorable) & $1,3,6,710$ & I don't always really try \\
\hline
\end{tabular}

\subsection{RESULTS}

Demographic Analysis

From 425 participants, seven data could not be obtained because the questionnaire is not complete, hence only 418 data was processed. 
Table 3 Demographic analysis (N=418)

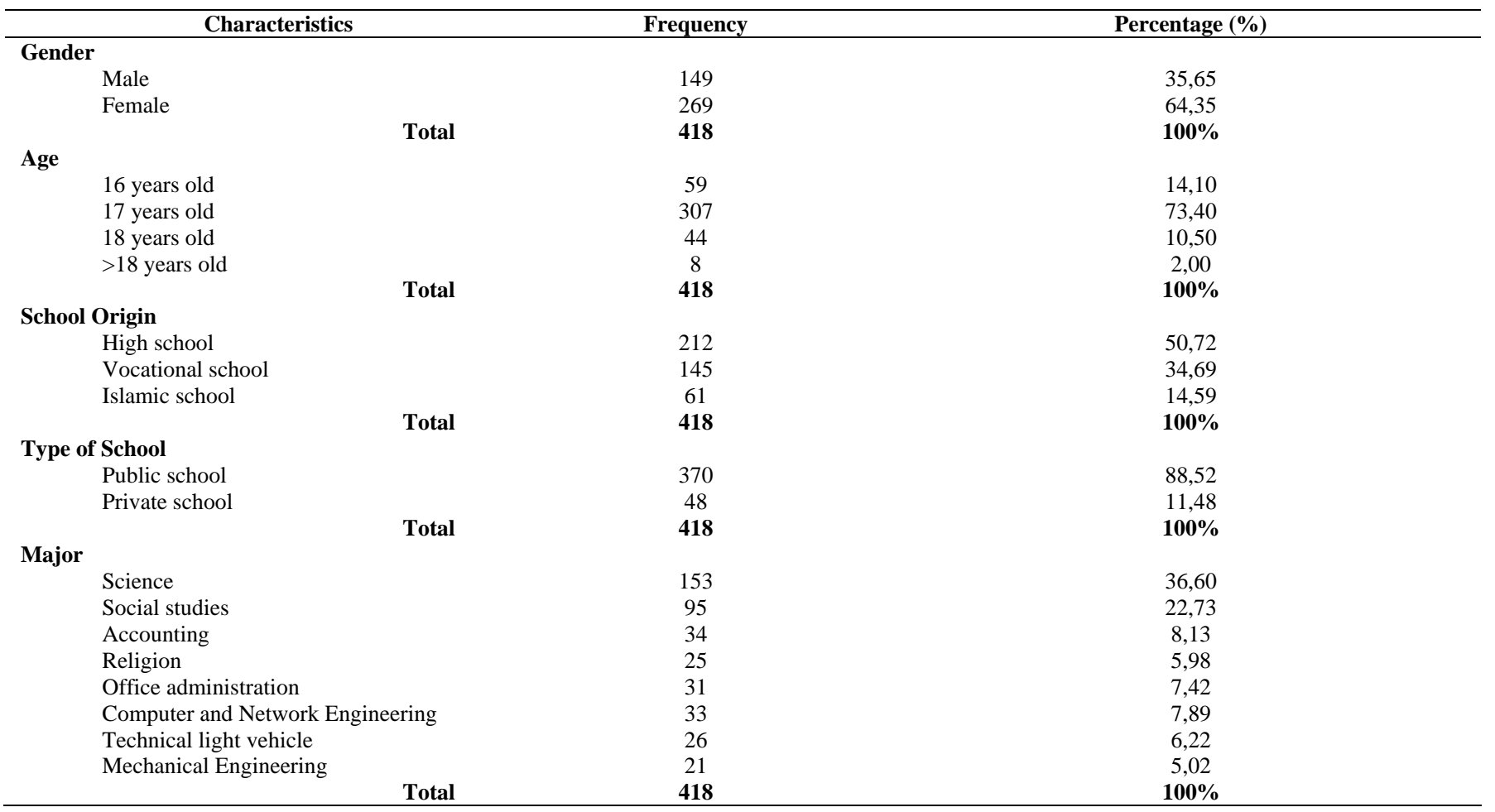

Table 3 shows the demography of 418 respondents. It can be concluded that the study participants were mostly female (64.35\%), aged 17 years $(73.40 \%)$, came from high school (50.72\%), public status schools $(88.52 \%)$, and Science majors $(36.60 \%)$.

\section{Normality Test}

Before further processing the data, a normality test is carried out to review the distribution of data whether it is a normal curve or not. The normality test is carried out with the Kolmogorov-Smirnov One-Sample test and results in the conclusion that this study has a normal data distribution. The result can be shown in Table 4 below

Table 4 Results of the normality test

\begin{tabular}{lll}
\hline & Variable & P-value \\
\hline Grit & 0,139 & $>0,05 ;$ Normal \\
Growth Mindset & 0,322 & $>0,05 ;$ Normal \\
\hline
\end{tabular}

\section{Correlation Analysis}

After the normality assumption is fulfilled, the parametric test is then continued to see the correlation between the three variables. The results showed that there is a significant positive relationship between the growth mindset and grit $(r=0.39 ; p<0.01)$. It means that higher score of growth mindset, higher score of grit.

\section{Regression Analysis}

To get the main results of the study, then testing the proposed hypothesis using simple regression statistical calculations. Table 5 and Table 6 will show the result of regression statistical between growth mindset and grit.

Table 5 Model summary-grit

\begin{tabular}{ccccc}
\hline Model & $\mathbf{R}$ & $\mathbf{R}^{2}$ & Adjusted R & Sig. F Change \\
1 & $0.39^{\mathrm{a}}$ & 0.15 & 0.15 & 0.000 \\
\hline a. Predictors: (constant), Growth mindset & &
\end{tabular}


Table 6 ANOVA ${ }^{\mathrm{a}}$

\begin{tabular}{clccccc}
\hline Model & & Sum of Squares & df & Mean Square & F & Sig. \\
\hline 1 & Regression & 3052.91 & 1 & 3052.91 & 75.39 & 0.000 \\
& Residual & 16846.69 & 416 & 40.50 & & \\
& Total & 19899.60 & 417 & & & \\
\hline
\end{tabular}

a. Dependent variable: Grit

b. Predictors: (constant), Growth mindset

Table 7 Regression coefficients

\begin{tabular}{|c|c|c|c|c|c|c|}
\hline \multirow{2}{*}{\multicolumn{2}{|c|}{ Model }} & \multicolumn{2}{|c|}{ Unstandardized Coefficient } & \multirow{2}{*}{$\begin{array}{c}\text { Standardized } \\
\text { Coefficient Beta }\end{array}$} & \multirow{2}{*}{$\mathbf{t}$} & \multirow{2}{*}{ Sig. } \\
\hline & & $\mathbf{B}$ & Standard Error & & & \\
\hline 1 & (Constant) & 26.49 & 3.40 & & 7.99 & 0.000 \\
\hline & Growth mindset & 0.45 & 0.05 & 0.39 & 8.68 & 0.000 \\
\hline
\end{tabular}

a. Dependent variable: Grit

Table 7 shows the growth mindset regression coefficient is 0.45 with a positive value and the probability value (p-value) is 0.0000 , which is less than the 0.05 significance level. That is, the growth mindset has a significant positive effect on grit. Then, the alternative hypothesis is accepted, growth mindset has a significant effect on the grit of high school students in Purbalingga as shown in the following Figure 1.

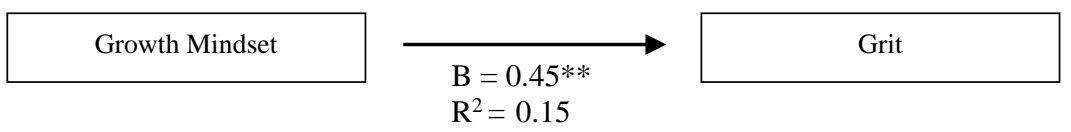

Figure 1 The role of growth mindset towards grit

\subsection{DISCUSSION}

This study aims to examine the relationship between the growth mindset and grit. The results of this study support the main research hypothesis, namely the growth mindset affects the grit of high school students in Purbalingga. Based on the results of the correlation test, it is known that there is a positive relationship between the variables. The relationship between the growth mindset and grit means that the more growth mindset of students, the grittier students. That is, the growth mindset predicts a higher level of grit. The findings of this study are in line with previous studies that students with a growth mindset tend to be grittier so that they are more diligent and focused on longterm learning (Dweck, Walton, \& Cohen, 2014; Chrisantiana \& Sembiring, 2017; Renaude-Dube, et al., 2015).

This study explains that each student has beliefs about intelligence, character, and ability to form a different set of assumptions to interpret and assess various information and events that occur around and aspects of his life. When in school, students will face various challenging conditions related to matters relating to themselves, social life, and academic life, especially in 12th grade who have higher academic demands. The existence of these challenges can be considered a difficulty that prevents him from going forward or vice versa, instead, it is considered an opportunity for him to learn and develop.

Students who see challenges as obstacles and view their abilities, character, and intelligence that cannot develop are called having a fixed mindset. A fixed mindset makes students lack positive beliefs related to their capacity, has a negative view of their business and work, attributes them to low ability so that they are less motivated and show less effort to achieve their goals. Conversely, students with a growth mindset will tend to have more constructive thinking, view challenging situations as opportunities for learning, so they don't give up easily when faced with challenges. In the end, students with a growth mindset will show persistence in their daily behavior. Including in academic life, students who have a growth mindset tend to be more motivated to learn when they encounter academic difficulties, have a great desire to develop abilities, and continue to strive to improve their performance focus on achieving desired goals.

Nowadays, various efforts related to improving the quality of education in Indonesia continue to be carried out, both for teachers, school entry systems, curriculum, school physical building, student cognitive abilities, and so on. Another thing that is no less important is the improved quality of non-cognitive factors (Polirstok, 2017), such as grit and growth mindset. Several studies explained interventions that can be done to increase both of them.

Grit in individuals can be grown from within themselves or from the environment (Duckworth, 2016; Gunderson et al, 2013). Therefore, schools or teachers can create experiences in students and a culture of grit in school through rules, activities, habits, and values that stimulate the growth and development of student grit. For example, providing readings about grit, discussing about grit and habits that can train grit, instill growth mindset in students, educate the importance of grit for students, create activities that can train student grit, invite students to have long-term goals and have high hopes for the future, and classifying students who are less grit with grittier students.

Based on this finding, programs related to a growth mindset can be done by teacher or school, such as: providing reading material for students that intelligence is plastic and the abilities they have today can continue to develop. The teacher can also educate students about the importance of a growth mindset, motivate students to have a growth mindset, and benefit from the growth mindset (Paunesku, Dweck, Romero, Smith, Yeager, \& Walton, 2015; Yeager \& Dweck, 2012; Good, Aronson, \& Inzlicht, 2003). Teachers as parties who interact a lot with students also can give compliments that emphasize more students' hard work than the innate character of students (Zentall \& Morris, 2010; Gunderson et al., 2013).

Growth mindset interventions by Paunesku, Dweck, Romero, Smith, Yeager, and Walton (2015) on high school students in America showed that growth mindset interventions influenced changes in students' beliefs about academic assignments, as an activity that was 
useful for learning tools and developing. They also believe that intelligence can be changed. For students who are at high risk of being dropped out (students who have a GPA of 2.0 or below or fail in one or more core subjects), growth mindset interventions also have a significant effect on increasing their GPA (Paunesku, Dweck, Romero, Smith, Yeager, \& Walton, 2015). This study means that a growth mindset can be learned to change students' beliefs, especially in students with underperformance (Rattan, Savani, Chugh, \& Dweck, 2015) even in students from low economies (Good, Aronson, \& Inzlicht, 2003).

This study has limitations. The population in this study was high school students in the Purbalingga area. Future studies can be replicated models in different populations and regions. Besides, this research sample is 12th-grade students. Furthermore, research can be done at different grade levels or levels of education to get results that may also be different.

\subsection{CONCLUSION}

This study successfully answers the research problem that a growth mindset has a significant effect on the grit of secondary school students in Purbalingga. These results can be a reinforcement for making intervention programs to improve grit of secondary school students in Purbalingga, one of them is through a growth mindset development program. This is intended so that students have a constructive way of thinking and view the academic challenges they face as opportunities for learning to motivate students to continue to strive to achieve goals and improve academic performance.

\section{References}

Akbağ, M., \& Ümmet, D. (2017). Predictive Role of Grit and Basic Psychological Needs Satisfaction on Subjective Well-Being for Young Adults. Journal of Education and Practice, 9, 127-135.

Bintamur, D.F. (2018). Validasi Struktural Skala Grit Untuk Remaja Dan Dewasa (GSCA). Unpublished

Blackwell, K.L., Trzesniewski, K.H., \& Dweck, C.S. (2007). Implicit Theories of Intelligence Predict Achievement Across An Adolescent Transition: A Longitudinal Study and an Intervention. Child Development, 78(1), 246-263.

Chrisantiana, T.G., \& Sembiring, T. (2017). Pengaruh Growth dan Fixed Mindset terhadap Grit pada Mahasiswa Fakultas Psikologi Universitas "X" Bandung. Humanitas (Jurnal Psikologi), 1(2), 133. https://doi.org/10.28932/humanitas.v1i2.422

Dweck, C. (2006). Mindset: The New Psychology of Success. New York: Random House

Duckworth, A. L., \& Quinn, P. D. (2009). Development and Validation of the Short Grit Scale (Grit-S). Journal of Personality Assessment, 91(2), 166-174. https://doi.org/10.1080/00223890802634290

Duckworth, A. L., Peterson, C., Matthews, M. D., \& Kelly, D. R. (2007). Grit: Perseverance and Passion for Long Term Goals. Journal of Personality and Social Psychology, 92, 1087-1101.

Duckworth, A. (2016). Grit: Kekuatan Passion dan Kegigihan. Jakarta: Gramedia

Dweck, C.S., Walton, G.M., \& Cohen, G.L. (2014). Academic Tenacity: Mindsets and Skills that Promote Long-Term Learning. Bill \& Melinda Gates Foundation. Retrieved from https://eric.ed.gov/?id=ED576649 Retrieved date: 28 December 2020

Gravetter, F.J., \& Forzano, L.B. (2012). Research Methods for The Behavioral Sciences (4th ed.). Belmont, CA: Wadsworth.

Hochanadel, A., \& Finamore, D. (2015). Fixed and Growth Mindset in Education and How Grit Helps Students Persist in the Face of Adversity. Journal of International Education Research (JIER), 11(1), 47. https://doi.org/10.19030/jier.v11i1.9099

Jach, H.K., Sun, J., Loton, D., Chin, T.-C., \& Waters, L.E. (2017). Strengths and Subjective Wellbeing in Adolescence: Strength-Based Parenting and the Moderating Effect of Mindset. Journal of Happiness Studies, 19, 567-586. https://doi.org/10.1007/s10902-016-9841-y

Jin, B., \& Kim, J. (2017). Grit, Basic Needs Satisfaction, and Subjective Well-Being. Journal of Individual Differences, 38(1), 29-35. https://doi.org/10.1027/1614$0001 / \mathrm{a} 000219$

King, R.B. (2017). A Fixed Mindset Leads to Negative Affect: The Relations Between Implicit Theories of Intelligence and Subjective Well-Being. Zeitschrift Für Psychologie, 225(2), 137-145. https://doi.org/10.1027/2151-2604/a000290

Paunesku, D., Walton, G.M., Romero, C., Smith, E.N., Yeager, D.S., \& Dweck, C.S. (2015). Mind-Set Interventions Are a Scalable Treatment for Academic Underachievement. Psychological Science, 26(6), 784-793. https://doi.org/10.1177/0956797615571017

Polirstok, S. (2017). Strategies to Improve Academic Achievement in Secondary School Students: Perspectives on Grit and Mindset. SAGE Open, 7(4), 1-9. 215824401774511. https://doi.org/10.1177/2158244017745111

Renaud-Dubé, A., Guay, F., Talbot, D., Taylor, G., \& Koestner, R. (2015). The relations between implicit intelligence beliefs, autonomous academic motivation, and school persistence intentions: a mediation model. Social Psychology of Education, 18(2), 255-272. https://doi.org/10.1007/s11218-014-9288-0

Shaari, Z.H., Amar, A., Harun, A. B., \& Zainol, M.R. (2017). Exploring the Mindsets and Well-Being Of Rural Secondary School Students in Perak, Malaysia. Global Business and Management Research: An International Journal, 9(1), 728-737.

Strayhorn, T.L. (2014). What Role Does Grit Play in Academic Success of Black Male Collegians At Predominately White Institutions? Journal of African American Studies, 18, 1-10.

Sturman, E.D., \& Zappala-Piemme, K. (2017). Development of the Grit Scale for Children and Adults and its Relation to Student Efficacy, Test Anxiety, and Academic Performance. Learning and Individual Differences, 59, 1-10. https://doi.org/10.1016/j.lindif.2017.08.004

Suzuki, Y., Tamesue, D., Asahi, K., \& Ishikawa, Y. (2015). Grit and Work Engagement: A Cross-Sectional Study. PLOS ONE, 10(9), e0137501. https://doi.org/10,1371/journal.pone.0137501

Yeager, D.S., \& Dweck, C.S. (2012). Mindsets that Promote Resilience: When Students Believe That Personal Characteristics Can Be Developed. Educational Psychologist, 47, 302-314. DOI:10,1080/00461520,2012.722805

Zeng, G., Hou, H., \& Peng, K. (2016). Effect of Growth Mindset on School Engagement and Psychological Well-Being of Chinese Primary and Middle School Students: The Mediating Role of Resilience. Frontiers in Psychology, 7, 1-8. https://doi.org/10.3389/fpsyg.2016.01873

Zhao, Y., Niu, G., Hou, H., Zeng, G., Xu, L., Peng, K., \& Yu, F. (2018). From Growth Mindset to Grit 